\title{
Non-Linear Optical Properties of Substituted Hexatriene: AM1 and ab Initio Quantum Chemical Calculations
}

\author{
Nouar Sofiane Labidi ${ }^{1,2}$ \\ ${ }^{1}$ Department of Chemistry, Faculty of Sciences, University of Sciences and Technology of Oran, Oran, Algeria \\ ${ }^{2}$ Centre Universitaire de Tamanrasset, Tamanrasset, Algeria \\ Email: labidi19722004@yahoo.fr
}

Received 17 April 2014; revised 20 May 2014; accepted 22 June 2014

Copyright $@ 2014$ by author and OALib.

This work is licensed under the Creative Commons Attribution International License (CC BY). http://creativecommons.org/licenses/by/4.0/

(c) (i) 0pen Access

\begin{abstract}
We report $a b$ initio studies of the dipole polarizabilities $(\alpha)$ and first static hyperpolarizabilities $(\beta)$ for a set of substituted hexatriene in which electron donating (D) and electron accepting (A) groups were introduced either end parts of the hexatriene chain $\mathrm{NO}_{2}-(\mathrm{CH}=\mathrm{CH})_{3}-\mathrm{D}$. Geometries of all molecules were optimized at the Hartree-Fock HF/6-311++G(2d,p) level of theory. Polarizabilities of these molecules were calculated at the same level of theory. To understand this phenomenon in the context of molecular orbital picture, we examined the molecular HOMOs and molecular LUMOs energies. The study revealed that the substituted hexatriene had large $\beta$ values and hence may have potential applications in the development of non linear optical materials.
\end{abstract}

\section{Keywords}

Ab Initio, Polarizability, Non-Linear Optics, Hyperpolarizability

Subject Areas: Computational Chemistry, Organic Polymer Materials, Quantum Chemistry, Theoretical Chemistry

\section{Introduction}

NLO materials have been attractive in recent years with respect to their future potential applications in the field of optoelectronic such as optical communication, optical computing, optical switching, and dynamic image processing [1] [2]. Due to their high molecular hyperpolarizabilities, organic materials display a number of significant nonlinear optical properties. NLO materials were categorized as multilayered semi-conductor structures, 
molecular based macroscopic assemblies and traditional inorganic solids. A variety of inorganic, organic and organometallic molecular systems have been studied for NLO activity [1]. The design strategy, used by many with success involves connecting donor (D) and acceptor (A) groups at the terminal positions of a П-bridge to create highly polarized molecules that could exhibit large molecular nonlinearity [3].

The delocalization of $\Pi$-electrons in these systems leads to large non resonant optical molecular polarizabilities. Besides, a number of quantum mechanical and experimental studies have shown that geometric changes caused by incorporation of push-pull end groups can enhance the nonlinear polarizabilities of conjugated molecules [4]-[6].

Experimental measurements and theoretical calculations on molecular hyperpolarizability become one of the key factors in the second-order NLO materials design [7] [8]. Theoretical determination of hyperpolarizability is quite useful both in understanding the relationship between the molecular structure and nonlinear optical properties. It also provides a guideline to experimentalists for the design and synthesis of organic NLO materials [9] [10].

A better understanding of the chemical substitutions effects on the NLO properties of new organic polymers constitutes an important step towards the advance of photonic technologies. Theoretical studies have drawn interesting conclusions on the side-substitution effects on the electric responses of trans PA chains. Marder et al. [11] [12] have investigated, on the basis of semi-empirical calculations, relations between structure and polarizabilities in donor-acceptor polyene compounds and have shown that the NLO responses of these systems can be optimized by varying the geometric parameter defined as bond length alternation (BLA).

Hayashi et al. [13] have calculated the linear and nonlinear polarizabilities in the side-chain direction (perpendicular to the main chain) of the PA chains with all $\mathrm{H}$ atoms substituted by fluorine, hydroxyl and cyano groups. Their HF/STO-3G results have shown that the coupling between electronic states of the side groups with those of the main chain increases the values of the perpendicular polarizabilities. Margulis and Gaiduk [14] have investigated the influence of the phenyl side groups on the third-order nonlinear optical susceptibility of trans PA chains. In the context of the tight-binding approximation, they have shown that an appropriate selection of side groups attached to the main chain can lead to a change of the sign of this property. Besides, effects of the incorporation of terminal donor and acceptor groups as well as the inclusion of singly and doubly charged defects on the polarizabilities of PA chains have also been studied [15]-[21]. These theoretical works have shown that, in general, such modifications increase the electric responses of conjugated polymers. Also general is the fact that the second hyperpolarizability is much more sensitive to substitution effects than the linear polarizability.

Our objective is to design a range of novel molecular systems, which show NLO activity. The approach is based on the concept of charge transfer (CT) between donor and acceptor through hexatriene linear chain. In this research work, isotropic static polarizability $(\alpha)$ and first hyperpolarizabilities $(\beta)$ are calculated using $a b$ initio method using Hartree-Fock level using 6-311G++(2d,p) basis set of disubstituted hexatriene $\mathrm{NO}_{2}-(\mathrm{CH}=\mathrm{CH})_{3}-\mathrm{D}$ with a number of $\Pi$-electron donor substituent at the end part using GAUSSIAN. The designing of systems with high charge transfer (CT) is the key to this part, as intra molecular CT between donor and acceptor will lead to a very large value for $\beta$.

\section{Computational Procedures}

All $a b$ initio calculations were made using GAUSSIAN 98 [22]. The geometries were optimized at the HartreeFock 6-311G++(2d,p) level. NLO calculations were performed at Hartree-Fock $a b$ initio level using the $6-311 \mathrm{G}^{++}(2 \mathrm{~d}, \mathrm{p})$ basis set, which has been found to be more than adequate for obtaining reliable trends in $(\beta)$ values. The semi empirical calculations using AM1 was performed using MOPAC 2000 [23].

\section{Results and Discussion}

\subsection{Selection of Basis Set}

To establish an appropriate computational method for studying the static polarizabilities of the substituted trans hexatriene, we compared the HF levels of theory for hexatriene using different basis sets.

Table 1 compares the experimental values of static isotropic polarizabilities for hexatriene with our calculations at the Hartree-Fock level using different basis sets, starting with the minimal basis set and then moved to higher basis sets by inserting polarization and diffusion functions. The basis sets incorporated in this study 
Table 1. Representative $a b$ initio static isotropic polarizabilities $(\alpha)$ for trans-hexatriene.

\begin{tabular}{cccccc}
\hline Basis set & $\alpha_{x x} / \mathrm{au}$ & $\alpha_{y y} / \mathrm{au}$ & $\alpha_{\text {zz }} / \mathrm{au}$ & $\langle\alpha\rangle / \mathrm{au}$ & Experiment $[26]\langle\alpha\rangle / \mathrm{au}$ \\
\hline HF/STO-3G & 90.855 & 34.038 & 6.763 & 43.885 & 87.456 \\
HF/3-21G & 136.892 & 53.327 & 15.474 & 68.564 & \\
HF/6-31G & 144.270 & 55.685 & 9.399 & 69.784 & \\
HF/6-31+G & 156.422 & 59.211 & 42.465 & 86.032 \\
HF/6-31++G & 156.464 & 59.397 & 42.857 & 86.239 & \\
HF/6-311G & 147.760 & 57.251 & 27.561 & 77.524 \\
HF/6-311+G & 154.374 & 59.134 & 42.365 & 85.291 \\
HF/6-311++G & 154.406 & 59.279 & 42.429 & 85.371 \\
HF/6-311++G(d,p) & 153.282 & 60.153 & 45.711 & 86.382 \\
HF/6-311G(2d,p) & 145.550 & 59.172 & 34.426 & 79.716 & \\
HF/6-311+G(2d,p) & 152.855 & 60.864 & 47.641 & 87.120 & \\
HF/6-311++G(2d,p) & 152.890 & 61.018 & 47.720 & 87.209 \\
HF/6-311++G(2d,2p) & 153.400 & 61.296 & 48.454 & 87.716 \\
\hline
\end{tabular}

include STO-3G, 3-21G, 6-31G, 6-31+G, 6-31++G, 6-311G, 6-311+G, 6-311++G, 6-311++G(d,p), 6-311G(2d,p), $6-311+G(2 d, p), 6-311++G(2 d, p)$ and $H F / 6-311++G(2 d, 2 p)$. Previous calculations for various small molecules indicate that two sets of polarization functions and a set of diffuse functions are generally needed to obtain satisfactory agreement with experimental polarizabilities [24]. However for the axial polarizability of larger polyenes, there is less need for large basis sets [25].

Examination of the values of polarizabilities shown in Table 1 illustrates the following well known conclusions: Extended, polarized basis sets are needed for polarizability calculations. A treatment of electron correlation is essential. Diffuse functions $(+,++)$ need to be included in the basis set. The polarizabilities of hexatriene calculated in the present work are 86.382, 87.120, and 87.209 (au) at the HF/6-311++G(d,p), HF/6-311+G(2d,p), and HF/6-311++G(2d,p) levels of theory, respectively. The value of 87.209 (au) fortuitously agrees perfectly with the experimental value of 87.456 (au) [26]. These results confirm once more that to accurately calculate the polarizability of smaller polyene one needs larger basis set [25]. Polarizability calculations performed at $a b$ initio using the HF/6-311++G(2d,p) basis set, was found to be more than adequate for obtaining reliable trends in $\langle\alpha\rangle$ values. We decided that the following procedure would be adopted for molecules in the series. Geometry optimisation and polarizability calculation at the HF/6-311++G(2d,p) level of theory.

\subsection{Geometry Optimization}

The optimized geometries (Figure 1) are essentially planar with the $\theta_{\mathrm{C}_{3} \mathrm{C}_{2} \mathrm{C}_{1} \mathrm{~N}_{7}}$ and $\theta_{\mathrm{C}_{4} \mathrm{C}_{5} \mathrm{C}_{6} \mathrm{~N}_{8}}$ torsion angles torsion angles close to $180^{\circ}$. However, molecules with - $\mathrm{NEt}_{2}$ and $-\mathrm{NMe}_{2}$ show a slight deviation from the planarity due to the steric interactions of protons of methyl and ethyl groups with the protons of hexatriene chain. The torsion and valence angles for $-\mathrm{NEt}_{2}$ and $-\mathrm{NMe}_{2}$ substitued groups are $\theta_{\mathrm{C}_{4} \mathrm{C}_{5} \mathrm{C}_{6} \mathrm{~N}_{8}}=-180^{\circ}$ and $-180^{\circ}$ and $\theta_{\mathrm{N}_{\mathrm{B}} \mathrm{C}_{6} \mathrm{C}_{5}}=$ $129^{\circ}$ and $123^{\circ}$ respectively. However, a dissimilar scenario occurs with an attractive interactions in molecule with - $\mathrm{NHOH}$ substituted groups where the oxygen atom of $-\mathrm{NHOH}$ interact with protons of hexatriene chain to form an $\mathrm{O} \cdots \mathrm{H}$ bond with $\mathrm{R}_{\mathrm{O} \cdots \mathrm{H}}=1.937 \AA$. The torsion and valence angles for this system are $\theta_{\mathrm{C}_{4} \mathrm{C}_{5} \mathrm{C}_{6} \mathrm{~N}_{8}}=174.4^{\circ}$ and $\theta_{\mathrm{N}_{8} \mathrm{C}_{6} \mathrm{C}_{5}}=125^{\circ}$. The first hyperpolarizability of molecule with $-\mathrm{NEt}_{2}$ groups is much greater than the analogous with $\mathrm{NHOH}, \mathrm{NH}_{2}, \mathrm{NHMe}, \mathrm{NEt}_{2}, \mathrm{NHNH}_{2}$ as donor groups. This is due to lack of planarity of substituted hexatriene chain due to the free rotation through the $\mathrm{C}_{6}-\mathrm{N}_{8}$ bonds. This will increase the overlap of interacting orbitals, which will eventually increase the CT from donor to acceptor through the linear chain. The functionality of amino groups $-\mathrm{NHOH}$, $-\mathrm{NH}_{2},-\mathrm{NHNH}_{2}$, $-\mathrm{NHMe}$, $-\mathrm{NHEt}$ and $-\mathrm{NEt}_{2}$, with the binding by $\mathrm{N}$ heteroatom, as a donor and $\mathrm{NO}_{2}$, as an acceptor, are the best $\mathrm{D} / \mathrm{A}$ pair among all investigated.

\subsection{Bond Length Alternation}

The works of Marder et al. [11] investigated, on the basis of semiempirical calculations, relations between structure and polarizabilities in donor-acceptor polyenes compounds have shown that the NLO responses of theses systems can be optimised by varying the geometric parameter defined as bond length alternation BLA. Table 2 give the BLA for optimised structure (Figure 2). 
Table 2. HF/6-311G++(2d,p) optimized bond length $(\AA)$ in substituted trans-hexatriene.

\begin{tabular}{|c|c|c|c|c|c|c|c|}
\hline \multirow{2}{*}{$\begin{array}{c}\text { Molecule } \\
\mathrm{NO}_{2} / \mathrm{Y}\end{array}$} & \multicolumn{5}{|c|}{ Bond length $(\AA)$} & \multirow{2}{*}{$\begin{array}{c}\text { BLA } \\
\text { (average) }\end{array}$} & \multirow{2}{*}{ Energy (au } \\
\hline & $\mathrm{C}_{1}=\mathrm{C}_{2}$ & $\mathrm{C}_{2}-\mathrm{C}_{3}$ & $\mathrm{C}_{3}=\mathrm{C}_{4}$ & $\mathrm{C}_{4}-\mathrm{C}_{5}$ & $\mathrm{C}_{5}=\mathrm{C}_{6}$ & & \\
\hline $\mathrm{H}$ & 1.341 & 1.438 & 1.352 & 1.446 & 1.340 & 0.097 & -435.42 \\
\hline $\mathrm{CH}_{3}$ & 1.342 & 1.436 & 1.354 & 1.442 & 1.344 & 0.092 & -474.47 \\
\hline $\mathrm{OCH}_{3}$ & 1.345 & 1.432 & 1.358 & 1.432 & 1.349 & 0.081 & -549.34 \\
\hline $\mathrm{OH}$ & 1.344 & 1.432 & 1.357 & 1.433 & 1.346 & 0.084 & -510.30 \\
\hline $\mathrm{NHOH}$ & 1.345 & 1.431 & 1.359 & 1.431 & 1.354 & 0.078 & -565.29 \\
\hline $\mathrm{NH}_{2}$ & 1.348 & 1.427 & 1.362 & 1.426 & 1.360 & 0.070 & -490.47 \\
\hline $\mathrm{NHNH}_{2}$ & 1.348 & 1.427 & 1.362 & 1.426 & 1.360 & 0.070 & -545.48 \\
\hline NHMe & 1.349 & 1.427 & 1.363 & 1.424 & 1.363 & 0.067 & -529.51 \\
\hline NHEt & 1.349 & 1.426 & 1.363 & 1.424 & 1.363 & 0.067 & -568.56 \\
\hline $\mathrm{NMe}_{2}$ & 1.349 & 1.426 & 1.363 & 1.426 & 1.366 & 0.067 & -568.54 \\
\hline $\mathrm{NEt}_{2}$ & 1.350 & 1.425 & 1.364 & 1.424 & 1.368 & 0.064 & -646.64 \\
\hline
\end{tabular}<smiles>[2H]C=C/C=C\C=C\[N+](=O)[O-]</smiles>

Figure 1. Illustration of the functional groups D and A investigated in this work.
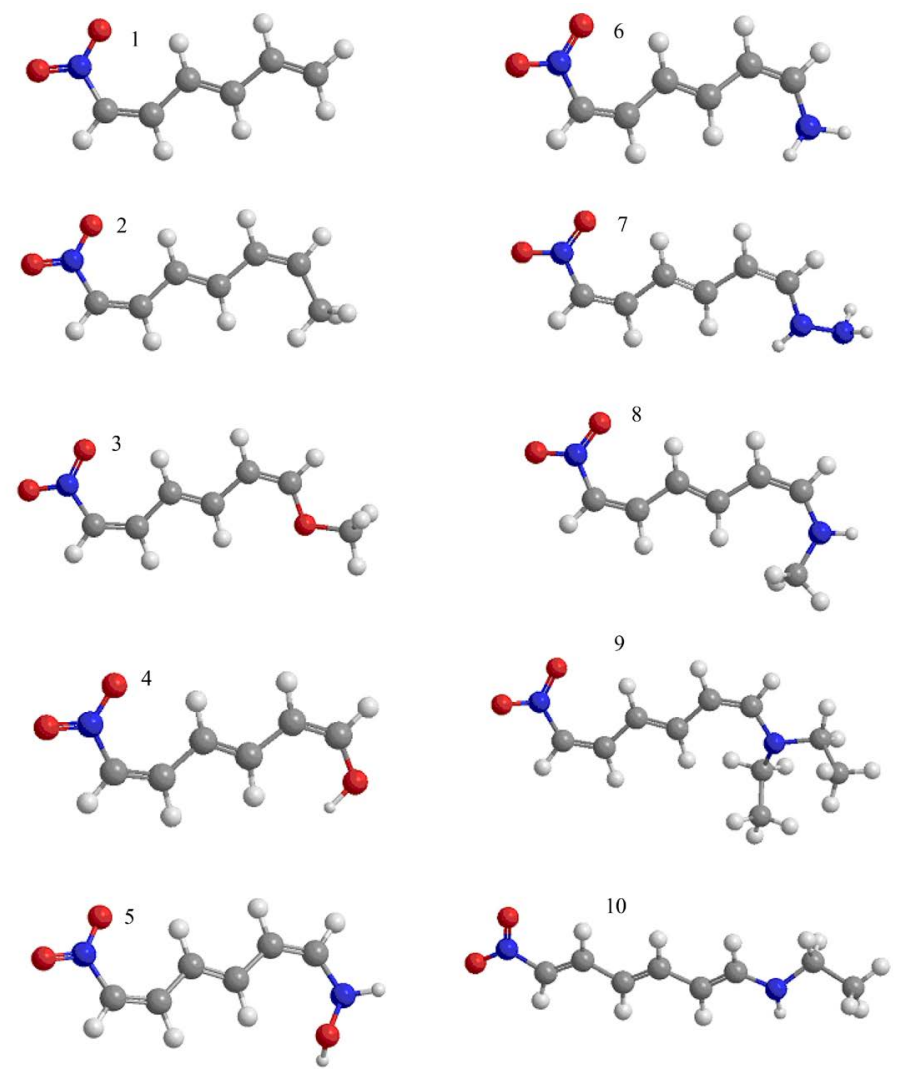

Figure 2. Optimised molecular structure of substituted hexatriene (1-10) by using HF/6-311G++(2d,p). 
It can be seen from Table 2 that, large and strong substituents $-\mathrm{NEt}_{2}$ and $-\mathrm{NMe}_{2}$ groups, make greater structural changes as compared to the small donor groups $-\mathrm{OCH}_{3},-\mathrm{CH}_{3}$ and -OH. The results first show that the substituents act to reduce the length of the single bonds and to increase the length of the double bonds. As a consequence, the average bond length alternation $\mathrm{BLA}_{\text {ave }}$ decreases from $\mathrm{NO}_{2} / \mathrm{H}$ to $\mathrm{NEt}_{2} / \mathrm{NO}_{2}$ by $\Delta \mathrm{l}=0.033 \AA$. However, the unsubstituted trans hexatriene present, at the same level of theory, a difference of $\Delta \mathrm{l}=0.042 \AA$ in average BLA. With regards to the bond length alternation BLA values in the middle and at the end, two different tendencies are found: 1) for the substituted groups $-\mathrm{H},-\mathrm{CH}_{3},-\mathrm{OCH}_{3},-\mathrm{OH},-\mathrm{NHOH},-\mathrm{NH}_{2},-\mathrm{NHNH}_{2}$, $-\mathrm{NHMe}$ the BLA increases when going from the middle to the end of the molecules. An increase ranging between 0.001 and $0.012 \AA$ in BLA is observed. 2) In the case of very strong substituted donor (-NHEt, $-\mathrm{NMe}_{2},-\mathrm{NEt}_{2}$ ) a small but reverse tendency is observed. A decrease of $0.002 \AA$ to $0.003 \AA$ in bond length alternation takes place from the middle to the end. It is, however important to note that globally it is the compound (11) with - $\mathrm{NEt}_{2}$ donor group that leads to the smallest BLA. For unsubstituted hexatriene, corresponding to the pure VB case, the BLA at the middle of the chain is $0.100 \AA$ is shorter than its end neighbours were the BLA is $0.109 \AA$ this presented a decrease of $0.009 \AA$ in bond length alternation takes place from the middle to the end.

\subsection{Polarizabilities and First Static Hyperpolarizability}

The results of the polarizability and the first static hyperpolarizability using ab initio at HF/6-311G++(2d,p) for all structures Figure 2 are given in the Table 3 and Table 4, respectively.

The mean polarizability was calculated from the polarizability components as [27]:

$$
\langle\alpha\rangle=\frac{1}{3}\left(\alpha_{x x}+\alpha_{y y}+\alpha_{z z}\right)
$$

Table 3 compares the calculated values of static isotropic polarizabilities for a number of nitrogen-containing hexatriene with a number of $\Pi$-electron donor substituent at the end parts calculated at the HF/6-311G++(2d,p) level of theory. For all series, the smallest enhancement is due to the pair $\mathrm{NO}_{2} / \mathrm{OH}$ values of about $112.192 \mathrm{au}$ for $\langle\alpha\rangle$ and the largest enhancement due to the pair $\mathrm{NO}_{2} / \mathrm{N}(\mathrm{Et})_{2}$ values of about 182.653 au for $\langle\alpha\rangle$. The largest increment of static isotropic polarizabilities $\Delta \alpha$ is seen to be due to $\mathrm{N}(\mathrm{Et})_{2}$ donor group $\Delta \alpha=76.233$ and the two smallest increments are due to $\mathrm{OH}$ and $\mathrm{CH}_{3}$ donor groups respectively ( $\Delta \alpha=5.772$ and 14.436). As regards to these substituted hexatriene, we are able to propose a decreasing classification, relatively to the $\langle\alpha\rangle$ polarizability. The established order is as follows: $\mathrm{N}(\mathrm{Et})_{2}>\mathrm{NHEt}>\mathrm{NHMe}>\mathrm{NHNH}_{2}>\mathrm{OCH}_{3}>\mathrm{NHOH}>\mathrm{NH}_{2}$ $\mathrm{CH}_{3}>\mathrm{OH}>\mathrm{H}$.

The graphical representations of dipole polarizabilities (computed at HF/6-311G++(2d,p)) versus the number of electrons are shown in Figure 3. It is apparent from this figure that there are significant correlations among components of a tensor and the number of electrons. All components of a tensor have linear relation with $\mathrm{N}_{\mathrm{e}}$. The excellent quality of linear correlation is evident from R coefficients, which are shown in Figure 3. Based on this fact, one can extrapolate $\langle\alpha\rangle$ and various components of a tensor for every unlimited disubstituted polyacetylene $\mathrm{NO}_{2}-(\mathrm{CH}=\mathrm{CH})_{\mathrm{n}}-\mathrm{D}$ series.

Table 4 shows all the $\beta$ components and the final $\beta_{\text {tot }}$ values calculated for the molecules under investigation. The complete equation for calculating the magnitude of $\beta_{\text {tot }}$ from GAUSSIAN98W output is given as follows [28] [29].

$$
\beta_{\text {tot }}=\left[\left(\beta_{x x x}+\beta_{x y y}+\beta_{x z z}\right)^{2}+\left(\beta_{y y y}+\beta_{y z z}+\beta_{y x x}\right)^{2}+\left(\beta_{z z z}+\beta_{z x x}+\beta_{z y y}\right)^{2}\right]^{\frac{1}{2}}
$$

Since the values of the first hyperpolarizability tensors of the output file of GAUSSIAN98W are reported in atomic units (au), the calculated values were converted into electrostatic units ( $\left.1 \mathrm{au}=8.6393 \times 10^{-33} \mathrm{esu}\right)$.

The magnitude of the first hyperpolarizability tensor of all molecules studied is dependent upon the availability of the lone pair of electrons on the nitrogen atom to conjugate with the hexatriene linear chain. The dramatic increase of first hyperpolarizability has been observed when the lone pair on the nitrogen atom of the donor group is forced to conjugate with the hexatriene linear chain, upon substitution on nitrogen of $\mathrm{NH}_{2}$ group with other groups, such as methyl, ethyl, hydroxyl etc. It is expected that the molecule with $\mathrm{NH}_{2}$ as the donor group would give a higher value for first hyperpolarizability with compare to the molecule where the donor group is $\mathrm{OCH}_{3}$. 
Table 3. Principal dipole polarizability tensor components HF/6-311G++(2d,p).

\begin{tabular}{ccccccc}
\hline $\begin{array}{c}\text { Molecule } \\
\mathrm{NO}_{2}-(\mathrm{CH}=\mathrm{CH})_{3}-\mathrm{D}\end{array}$ & $\alpha_{x x} / \mathrm{au}$ & $\alpha_{y y} / \mathrm{au}$ & $\alpha_{z z} / \mathrm{au}$ & $\langle\alpha\rangle / \mathrm{au}$ & $\begin{array}{c}\text { Increment } \\
\Delta \alpha /(\mathrm{au})\end{array}$ & $\mathrm{N}_{\mathrm{e}}$ \\
\hline $\mathrm{H}$ & 195.410 & 72.224 & 51.626 & 106.420 & 0.00 & 66 \\
$\mathrm{OH}$ & 206.252 & 77.152 & 53.172 & 112.192 & 5.772 & 74 \\
$\mathrm{CH}_{3}$ & 219.003 & 83.138 & 60.429 & 120.856 & 14.436 & 74 \\
$\mathrm{NH}_{2}$ & 226.835 & 81.320 & 57.140 & 121.765 & 15.345 & 74 \\
$\mathrm{NHOH}^{\mathrm{OCH}}{ }_{3}$ & 224.094 & 88.757 & 59.373 & 124.074 & 17.654 & 82 \\
$\mathrm{NHNH} 2$ & 235.284 & 87.198 & 63.691 & 128.724 & 22.304 & 82 \\
$\mathrm{NHMe}$ & 248.840 & 87.461 & 63.743 & 133.348 & 26.928 & 82 \\
$\mathrm{NHEt}$ & 246.287 & 95.615 & 65.935 & 135.945 & 29.525 & 82 \\
$\mathrm{~N}(\mathrm{Et})_{2}$ & 284.598 & 103.775 & 75.970 & 154.781 & 48.361 & 90 \\
\hline
\end{tabular}

$\Delta \alpha$ : polarizability difference on substitution of $\mathrm{Y}$ into $\mathrm{NO}_{2}-(\mathrm{CH}=\mathrm{CH})_{3}-\mathrm{Y}$.

Table 4. All $\beta$ components and $\beta_{\text {tot }}$ calculated at HF level using HF/6-311G++(2d,p) basis set by GAUSSIAN98W for all substituted hexatriene.

\begin{tabular}{|c|c|c|c|c|c|c|c|c|c|c|c|c|}
\hline Molecule & $\beta_{X X X}$ & $\beta_{X X Y}$ & $\beta_{X Y Y}$ & $\beta_{Y Y Y}$ & $\beta_{X X Z}$ & $\beta_{X Y Z}$ & $\beta_{Y Y Z}$ & $\beta_{X Z Z}$ & $\beta_{Y Z Z}$ & $\beta_{Z Z Z}$ & $\beta_{\text {tot }} / \mathrm{au}$ & $\begin{array}{c}\beta_{\text {tot }} \times 10^{-30} \\
\quad(\mathrm{esu})\end{array}$ \\
\hline 1 & 486.9406 & 28.9009 & 108.2542 & 39.5937 & -0.2455 & -0.0892 & 0.0388 & -65.6319 & 11.0294 & -0.0182 & 535.500 & 4.626 \\
\hline 2 & -828.3495 & 80.6883 & -123.1313 & 40.1633 & 0.0562 & 0.1294 & -0.0603 & 45.0978 & 4.2979 & 0.0780 & 914.982 & 7.904 \\
\hline 3 & -1055.3987 & -92.2003 & -147.7486 & -49.0719 & 0.9528 & -0.6031 & -0.5544 & 76.7740 & 34.6523 & 1.8092 & 1131.41 & 9.774 \\
\hline 4 & -1043.0015 & 94.8534 & -161.4728 & 32.7181 & -0.0319 & 0.0075 & -0.0027 & 26.4609 & -10.1908 & 0.0174 & 1183.847 & 10.227 \\
\hline 5 & -1258.0218 & 72.1084 & -165.6371 & 32.7033 & -11.9212 & 0.3332 & 3.2941 & 18.8223 & -9.9188 & -2.2753 & 1408.080 & 12.164 \\
\hline 6 & 1486.3942 & 132.4900 & 184.8757 & 22.2281 & 17.1001 & 5.3185 & 1.7527 & -46.1323 & -3.8384 & 5.8278 & 1632.313 & 14.102 \\
\hline 6 & 1616.6333 & -134.6059 & 158.9510 & -39.4687 & 79.0381 & -6.6086 & 4.7495 & -74.8318 & 19.3561 & 31.5056 & 1711.662 & 14.787 \\
\hline 7 & 1856.1625 & 187.1026 & 212.6315 & 64.6901 & -0.0252 & -9.0031 & 3.6189 & -17.9819 & -2.3930 & 19.7970 & 2066.053 & 17.849 \\
\hline 8 & 2224.9184 & 234.3071 & 190.3488 & 94.0446 & -57.2048 & -4.9263 & -28.7311 & -114.7208 & 1.9063 & -72.2354 & 2329.506 & 20.125 \\
\hline 9 & 3406.1656 & 646.6501 & -140.6919 & -30.0006 & 42.9215 & -18.6552 & 13.5288 & -68.8335 & 7.8635 & 37.4629 & 3258.426 & 28.150 \\
\hline
\end{tabular}

The result indicates also that the magnitude of first hyperpolarizability $\beta$ of molecules is dependent upon the availability of the lone pair of electrons on the nitrogen atom to conjugate with the hexatriene linear chain. The dramatic increase of first hyperpolarizability has been observed when the lone pair on the nitrogen atom of the donor groups is forced to conjugate with the hexatriene linear chain, upon substitution on nitrogen of - $\mathrm{NH}_{2}$ group with other groups, such as methyl, ethyl, hydroxyl, etc. Molecule with - $\mathrm{NEt}_{2}$ group shows 54\% and 70\% increase of first hyperpolarizability with compare to molecule with $-\mathrm{OCH}_{3}$ and $-\mathrm{CH}_{3}$ donor groups, respectively. As regards to the П-electron donating capacity of the typical substituted groups, we are able to propose a decreasing classification, relatively to b hyperpolarizability. The established order is as follows: $\mathrm{NEt}_{2}>\mathrm{NMe}_{2}>\mathrm{NHEt}>\mathrm{NHMe}>$ $\mathrm{NHNH}_{2}>\mathrm{NH}_{2}>\mathrm{NHOH}>\mathrm{OCH}_{3}>\mathrm{OH}>\mathrm{CH}_{3}>\mathrm{H}$.

The molecular hyperpolarizability value of molecule with $-\mathrm{NEt}_{2}$ group $\left(28.15 \times 10^{-30}\right.$ esu) is about 200 times grater than that of urea $\left(0.14 \times 10^{-30} \mathrm{esu}\right)$ [30], 10 times grater than that of 2,4,6-trinitrophenol $\left(2.99 \times 10^{-30} \mathrm{esu}\right)$ [31] and the same with the fluorenyl derivative (7-nitro-9H-fluoren-2-ylamine $30.20 \times 10^{-30} \mathrm{esu}$ ) [32].

The $a b$ initio optimization of all molecules in this investigation shows that the molecules are almost planer. However, molecules 8, 9 and 10 show a slight deviation from the planarity due to the steric interactions of protons of methyl and ethyl groups with the protons of hexatriene chain. The same scenario occurs in molecule 5 


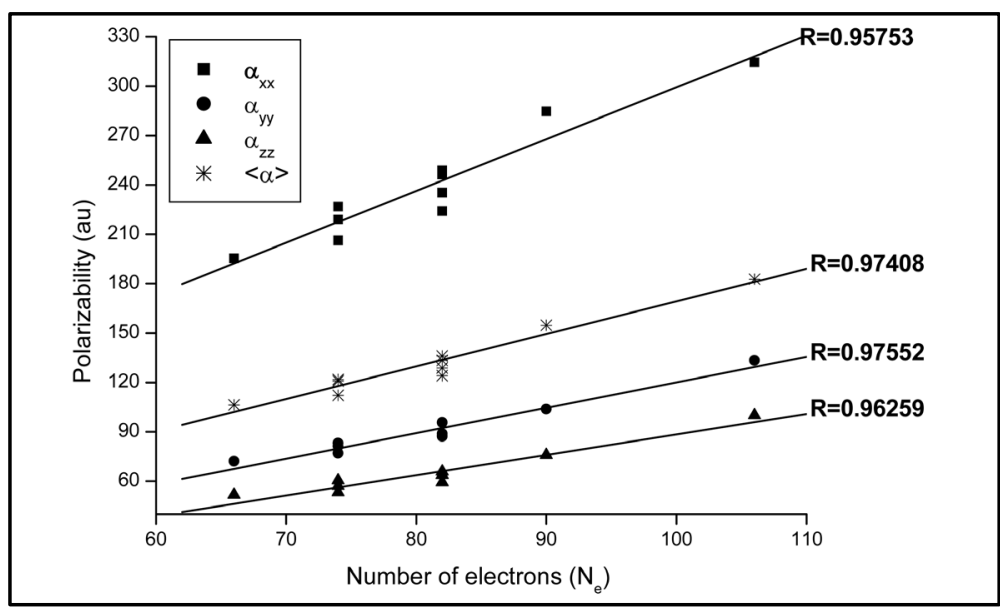

Figure 3. Graphical representation of calculated dipole polarizabilities for substituted hexatriene by the HF/6-311G++(2d,p).

where $\mathrm{O}$ atoms of $\mathrm{NHOH}$ interact with protons of hexatriene chain. The first hyperpolarizability of molecule 10 is much greater than the analogous with $\mathrm{NHOH}, \mathrm{NH}_{2}, \mathrm{NHMe}, \mathrm{N}(\mathrm{Et})_{2}, \mathrm{NHNH}_{2}$ as donor groups. This is possibly due to lack of planarity of hexatriene chain due to the free rotation through the carbone-carbone $\sigma$-bond. This will increase the overlap of interacting orbitals, which will eventually increase the CT from donor to acceptor through the linear chain.

To understand this phenomenon in the context of molecular orbital picture, we examined the molecular HOMOs and molecular LUMOs generated via GAUSSIAN98W. The results for all disubstituted hexatriene are summarized graphically in Figure 4. Figure 5 shows the variation of HOMO-LUMO difference for all disubstituted hexatriene.

As shown in Figure 4 substitution of different electron donor groups on nitrogen of $\mathrm{NH}_{2}$ group in molecules 1 - 10 increases the energy of the molecular HOMO, while leaving the LUMO energy essentially unchanged due to the same acceptor group. Thus, the energy gap decreases with the substitution on nitrogen of $\mathrm{NH}_{2}$ and produces a larger hyperpolarizability.

Figure 5 shows the variation of first hyperpolarizability and energy gap $E_{\text {gap }}$ for molecules under investigation. The enhancement of first hyperpolarizability of these molecules is directly related to the HOMO-LUMO energy gap, an inverse relationship was found between $E_{\text {gap }}\left(E_{\text {LUMO }}-E_{\text {LUMO }}\right)$ and hyperpolarizability. Compounds with the smallest energy gap produce the larger $\beta_{\text {tot }}$ value, while the larger energy gap produces a decrease in hyperpolarizability value. It could be interesting to synthesize compounds 5 - 10 having the greatest and the lowest, respectively $\beta_{\text {tot }}$ and $\mathrm{E}_{\text {gap }}$ values.

Table 5 shows the comparison of linear and non-linear optical properties of disubstituted hexatriene calculated using different methods.

The HF/6-311G++(2d,p) polarizabilities are generally a few percent higher than the corresponding values calculated at AM1 level (15\% for $\mathrm{NHNH}_{2}, 10 \%$ for $\mathrm{OH}, 9.79 \%$ for $\mathrm{N}(\mathrm{Et})_{2}, 8.40 \%$ for NHEt, $6.87 \%$ for NHMe and $5 \%$ for $\left.\mathrm{NH}_{2}\right)$. There is good absolute agreement between the HF/6-311G++(2d,p) values and the AM1 results, they give a correlation coefficient of 0.98 which means that AM1 results can be accurately scaled for such molecules. The AM1 produces better results for polarizability which are comparable with the experimental results and the $a b$ initio value calculated at HF/6-311++G(2d,p) level.

AM1 semi empirical method yielded extremely higher value for the hyperpolarizability. The AM1 method showed a much higher value, which is divergent with that of $a b$ initio level. It was found that the AM1 semiempirical value of $\beta_{\text {tot }}$ is $16 \%-60 \%$ more than the ab initio value calculated at $\mathrm{HF} / 6-311++\mathrm{G}(2 \mathrm{~d}, \mathrm{p})$ level. Therefore, AM1 method would not be a better option for calculating hyperpolarizability of these types of molecules.

\section{Conclusions}

It is evident that the first hyperpolarizability tensor of substituted hexatriene strongly depends on the electronic 


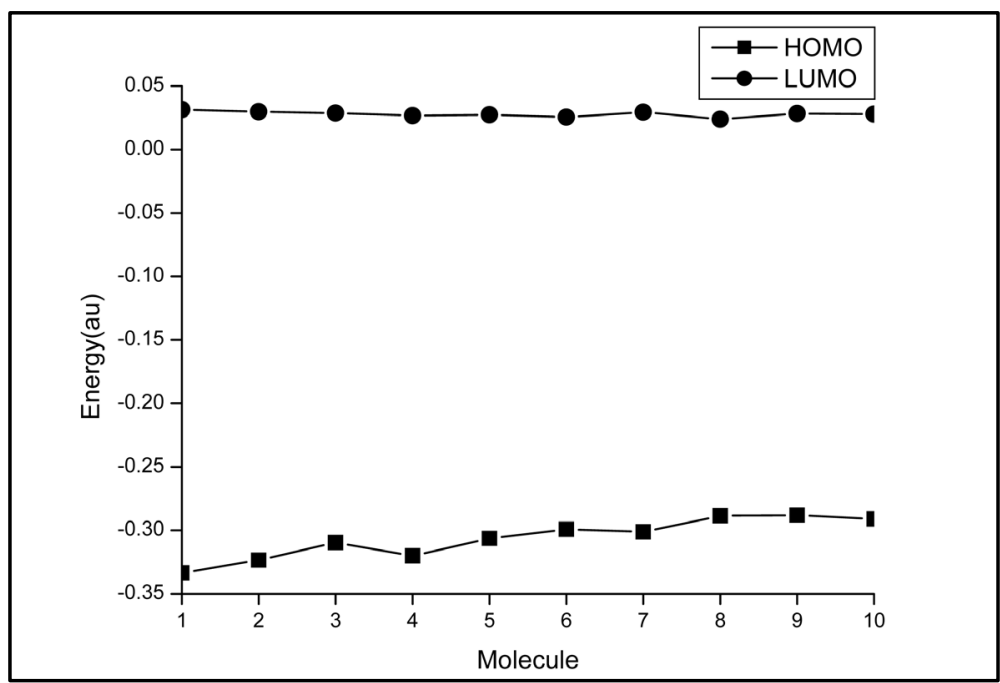

Figure 4. Changes in the energy levels of HOMO-LUMO orbital of molecule $1-10$.

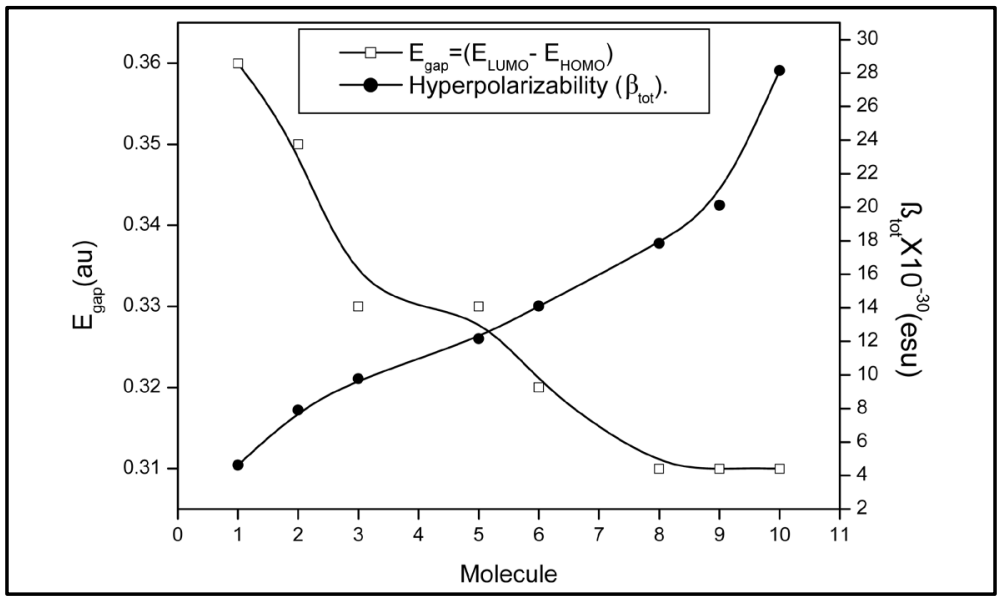

Figure 5. Variation of $\beta_{\text {tot }}$ and $\mathrm{E}_{\text {gap }}$ values for compounds under study.

Table 5. Comparison of linear and non-linear optical properties of molecules 1-10 calculated using both $a b$ initio and semi empirical levels of theory.

\begin{tabular}{|c|c|c|c|c|}
\hline \multirow{2}{*}{ Molecule } & \multicolumn{2}{|c|}{$\mathrm{HF} / 6-311 \mathrm{G}++(2 \mathrm{~d}, \mathrm{p})$} & \multicolumn{2}{|c|}{ AM1 } \\
\hline & $\langle\alpha\rangle \times 10^{-30}(\mathrm{esu})$ & $\beta_{\mathrm{tot}} \times 10^{-30}(\mathrm{esu})$ & $\langle\alpha\rangle \times 10^{-30}(\mathrm{esu})$ & $\beta_{\mathrm{tot}} \times 10^{-30}(\mathrm{esu})$ \\
\hline 1 & 0.919 & 4.626 & 0.781 & 7.671 \\
\hline 2 & 1.044 & 7.904 & 0.909 & 11.459 \\
\hline 3 & 1.112 & 9.774 & 0.980 & 16.430 \\
\hline 4 & 0.969 & 10.227 & 0.871 & 14.210 \\
\hline 5 & 1.071 & 12.164 & 0.959 & 15.839 \\
\hline 6 & 1.051 & 14.102 & 0.992 & 25.565 \\
\hline 7 & 1.152 & 14.787 & 0.977 & 17.650 \\
\hline 8 & 1.174 & 17.849 & 1.093 & 27.800 \\
\hline 9 & 1.577 & 20.125 & 1.423 & 49.722 \\
\hline 10 & 1.337 & 28.150 & 1.224 & 37.181 \\
\hline
\end{tabular}


structure of the molecule. The molecules linked together through the linear chain tend to rotate, about carboncarbon $\sigma$-bond; this will increase overlap of interacting orbitals, which eventually increase the CT from donor to acceptor through the linear moiety.

The HOMO-LUMO calculations show that the first hyperpolarizability of the compounds is directly related to the HOMO-LUMO energy gap. This is the highest in molecules 10 while the smallest is in 2, which has the highest energy gap. The study reveals that the substituted hexatriene has important first static hyperpolarizabilities. They may have potential application in the development of NLO materials.

It is important to stress that, in the calculated $\beta$ values, we do not take into account the effect of the field strength on the nuclear positions. We evaluate only the electronic component of $\beta$. The vibrational contributions which, for conjugated systems, can be important depending on the NLO process are the subject of further investigations.

\section{References}

[1] Kanis, D.R., Ratner, M.A. and Marks, T. (1994) Design and Construction of Molecularassemblie Nonlinearities. Chemical Reviews, 94, 195. http://dx.doi.org/10.1021/cr00025a007

[2] Prasad, P.N. and Williams, D.J. (1991) Introduction to Nonlinear Optical Effects in Molecules and Polymers. Wiley, New York.

[3] Masraqui, S.H., Kenny, R.S., Ghadigaonkar, S.G., Krishnan, A., Bhattacharya, M. and Das, P.K. (2004) Synthesis and Nonlinear Optical Properties of Some Donor-Acceptor Oxadiazoles. Optical Materials, 27, 257-260. http://dx.doi.org/10.1016/j.optmat.2004.04.006

[4] Sinclair, M., Moses, D., Heeger, A.J., Vilhelmsson, K., Valk, B. and Salour, M. (1987) Measurement of the Third Order Susceptibility of Trans-Polyacetylene by Third Harmonic Generation. Solid State Communications, 61, 221-225. http://dx.doi.org/10.1016/0038-1098(87)91006-4

[5] Chemla, D.S. and Zyss, J. (1987) Nonlinear Optical Properties of Organic Molecules and Crystals. Academic Press, New York.

[6] Williams, D.J. (1985) Nonlinear Optical Properties of Organic and Polymeric Materials. American Chemical Society Symposium Series 233, American Chemical Society, Washington DC.

[7] Rice, J.E. and Handy, N.C. (1991) The Calculation of Frequency-Dependent Polarizabilities as Pseudo-Energy Derivatives. Journal of Chemical Physics, 94, 4959. http://dx.doi.org/10.1063/1.460558

[8] Li, H., Han, K., Shen, X., Lu, Z., Huang, Z., Zhang, W., Zhang, Z. and Bai, L. (2006) The First Hyperpolarizabilities of Hemicyanine Cationic Derivatives Studied by Finite-Field (FF) Calculations. Journal of Molecular Structure: THEOCHEM, 767, 113-118. http://dx.doi.org/10.1016/j.theochem.2006.05.008

[9] Labidi, N.S., Djebaili, A. and Rouina, I. (2011) Substitution Effects on the Polarizability (A) and First Hyperpolarizability $(\beta)$ of All-Trans Hexatriene. Journal of Saudi Chemical Society, 15, 29-37. http://dx.doi.org/10.1016/j.jscs.2010.09.010

[10] Garcia-Borràs, M., Solà, M., Luis, J.M. and Kirtman, B. (2012) Electronic and Vibrational Nonlinear Optical Properties of Five Representative Electrides. Journal of Chemical Theory and Computation, 8, 2688-2697. http://dx.doi.org/10.1021/ct300433q

[11] Marder, S.R., Gorman, C.B., Meyers, F., Perry, J.W., Bourhill, G., Bredas, J.L. and Pierce, B.M. (1994) A Unified Description of Linear and Nonlinear Polarization in Organic Polymethine Dyes. Science, 265, 632-635. http://dx.doi.org/10.1126/science.265.5172.632

[12] Meyers, F., Mader, S.R., Pierce, B.M. and Bredas, J.L. (1994) Electric Field Modulated Nonlinear Optical Properties of Donor-Acceptor Polyenes: Sum-over-States Investigation of the Relationship between Molecular Polarizabilities $(\alpha$, $\beta$, and $\gamma$ ) and Bond Length Alternation. Journal of the American Chemical Society, 116, 10703-10714. http://dx.doi.org/10.1021/ja00102a040

[13] Hayashi, S., Yabushita, S. and Imamura, A. (1991) Ab Initio Calculations of Linear and Nonlinear Polarizabilities in the Side-Chain Direction on the Conjugated Polymers. Chemical Physics Letters, 179, 405-409. http://dx.doi.org/10.1016/0009-2614(91)85174-U

[14] Margulis, V.A. and Gaiduk, E.A. (1998) The Effect of Side Chain Substituents on Third-Order Optical Nonlinearity of Conjugated Polymers: A Theoretical Study. Synthetic Metals, 97, 175-190. http://dx.doi.org/10.1016/S0379-6779(98)00122-2

[15] Oliveira, L.N., Amaral, O.A.V., Castro, M.A. and Fonseca, T.L. (2003) Static Polarizabilities of Doubly Charged Polyacetylene Oligomers: Basis Set and Electron Correlation Effects. Chemical Physics, 289, 221-230. http://dx.doi.org/10.1016/S0301-0104(03)00026-0 
[16] Champagne, B., Spassova, M., Jadin, J.B. and Kirtman, B. (2002) Ab Initio Investigation of Doping-Enhanced Electronic and Vibrational Second Hyperpolarizability of Polyacetylene Chains. Journal of Chemical Physics, 116, 3935. http://dx.doi.org/10.1063/1.1446046

[17] Fonseca, T.L., Castro, M.A., Cunha, C. and Amaral, O.A.V. (2001) Ab Initio Polarizabilities Calculations of Singly Charged Polyacetylene Oligomers. Synthetic Metals, 123, 11-15. http://dx.doi.org/10.1016/S0379-6779(00)00576-2

[18] An, Z. and Wong, K.Y. (2001) Long Chain-Length Behaviors of Optical Nonlinearities of Substituted Polyenic Chains with Charged Topological Defects. Journal of Chemical Physics, 114, 1010. http://dx.doi.org/10.1063/1.1322058

[19] Champagne, B., Deumens, E. and Ohrn, Y. (1997) Vibrations and Soliton Dynamics of Positively Charged Polyacetylene Chains. Journal of Chemical Physics, 107, 5433. http://dx.doi.org/10.1063/1.474249

[20] de Melo, C.P. and Fonseca, T.L. (1996) Ab Initio Polarizabilities of Polyenic Chains with Conformational Defects. Chemical Physics Letters, 261, 28-34. http://dx.doi.org/10.1016/0009-2614(96)00937-2

[21] Zhu, W.H., Wu, G.S. and Jiang, Y.S. (2002) Substitution Effects on the Molecular Structures and the Longitudinal Molecular Polarizabilities of All-Trans Polyacetylene Oligomers of Increasing Size. International Journal of Quantum Chemistry, 86, 390-400. http://dx.doi.org/10.1002/qua.1125

[22] Frisch, M.J., Trucks, G.W., Schlegel, H.B., Scuseria, G.E., Robb, M.A., Cheeseman, J.R., Zakrzewski, V.G., Montgomery, J.A., Stratmann, R.E., Burant, J.C., Dapprich, S., Millam, J.M., Daniels, A.D., Kudin, K.N., Strain, M.C., Farkas, O., Tomasi, J., Barone, V., Cossi, M., Cammi, R., Mennucci, B., Pomelli, C., Adamo, C., Clifford, S., Ochterski, J., Petersson, G.A., Ayala, P.Y., Cui, Q., Morokuma, K., Malick, D.K., Rabuck, A.D., Raghavachari, K., Foresman, J.B., Cioslowski, J., Ortiz, J.V., Stefanov, B.B., Liu, G., Liashenko, A., Piskorz, P., Komaromi, I., Gomperts, R., Martin, R.L., Fox, D.J., Keith, T., Al-Laham, M.A., Peng, C.Y., Nanayakkara, A., Gonzalez, C., Challacombe, M., Gill, P.M.W., Johnson, B., Chen, W., Wong, M.W., Andres, J.L., Gonzalez, C., Head-Gordon, M., Replogle, E.S. and Pople, J.A. (1998) Gaussian Inc., Pittsburgh.

[23] Stewart, J.J.P. (1999) MOPAC 2002. Fujitsu Limited, Tokyo.

[24] Sadlej, A.J. (1988) Medium-Size Polarized Basis Sets for High-Level Correlated Calculations of Molecular Electric Properties. Collection of Czechoslovak Chemical Communications, 53, 1995. http://dx.doi.org/10.1135/cccc19881995

[25] Hurst, G.J.B., Dupuis, M. and Clementi, E. (1988) Ab Initio Analytic Polarizability, First and Second Hyperpolarizabilities of Large Conjugated Organic Molecules: Applications to Polyenes $\mathrm{C}_{4} \mathrm{H}_{6}$ to $\mathrm{C}_{22} \mathrm{H}_{24}$. Journal of Chemical Physics, 89, 385. http://dx.doi.org/10.1063/1.455480

[26] Weast, C.R. (1985-86) CRC Hand Book of Chemistry and Physics. 66th Edition, CRC Press, Boca Raton.

[27] Sophy, K.B., Calaminici, P. and Pal, S. (2007) Density Functional Static Dipole Polarizability and First-Hyperpolarizability Calculations of Nan $(\mathrm{n}=2,4,6,8)$ Clusters Using an Approximate CPKS Method and Its Comparison with MP2 Calculations. Journal of Chemical Theory and Computation, 3, 716-727. http://dx.doi.org/10.1021/ct6003627

[28] Tillekeratne, A.D., de Silva, R.M. and Nalin de Silva, K.M. (2003) Push-Pull Porphyrins as Non-Linear Optical Materials: Ab Initio Quantum Chemical Calculations. Journal of Molecular Structure: THEOCHEM, 638, 169-176. http://dx.doi.org/10.1016/S0166-1280(03)00566-9

[29] Liyanage, P.S., de Silva, R.M. and Nalin de Silva, K.M. (2003) Nonlinear Optical (NLO) Properties of Novel Organometallic Complexes: High Accuracy Density Functional Theory (DFT) Calculations. Journal of Molecular Structure: THEOCHEM, 639, 195-201. http://dx.doi.org/10.1016/j.theochem.2003.08.009

[30] Wu, K.C., Snijders, J.G. and Lin, C.S. (2002) Reinvestigation of Hydrogen Bond Effects on the Polarizability and Hyperpolarizability of Urea Molecular Clusters. Journal of Physical Chemistry B, 106, 8954-8958. http://dx.doi.org/10.1021/jp014181i

[31] Chang, L.T., Tam, W., Stevensen, S.H., Meredith, G.R., Rikken, G. and Marder, S.R. (1991) Experimental Investigations of Organic Molecular Nonlinear Optical Polarizabilities. 1. Methods and Results on Benzene and Stilbene Derivatives. Journal of Physical Chemistry, 95, 10631-10643. http://dx.doi.org/10.1021/j100179a026

[32] Thanthiriwatte, K.S. and Nalin de Silva, K.M. (2002) Non-Linear Optical Properties of Novel Fluorenyl DerivativesAb Initio Quantum Chemical Calculations. Journal of Molecular Structure: THEOCHEM, 617, 169-175. http://dx.doi.org/10.1016/S0166-1280(02)00419-0 